\title{
To save the snake: education and conservation at the Madras Snake Park
}

\author{
Diana Seshadri
}

The major obstacle to snake conser- pervades the country and how the Park is vation in India, and probably in other seeking to overcome the problem by a countries too, is human fear. The author programme of public education.

visited the Madras Snake Park in 1980 and describes the fear of snake bite that Spectacled cobra (M. Krishnan).

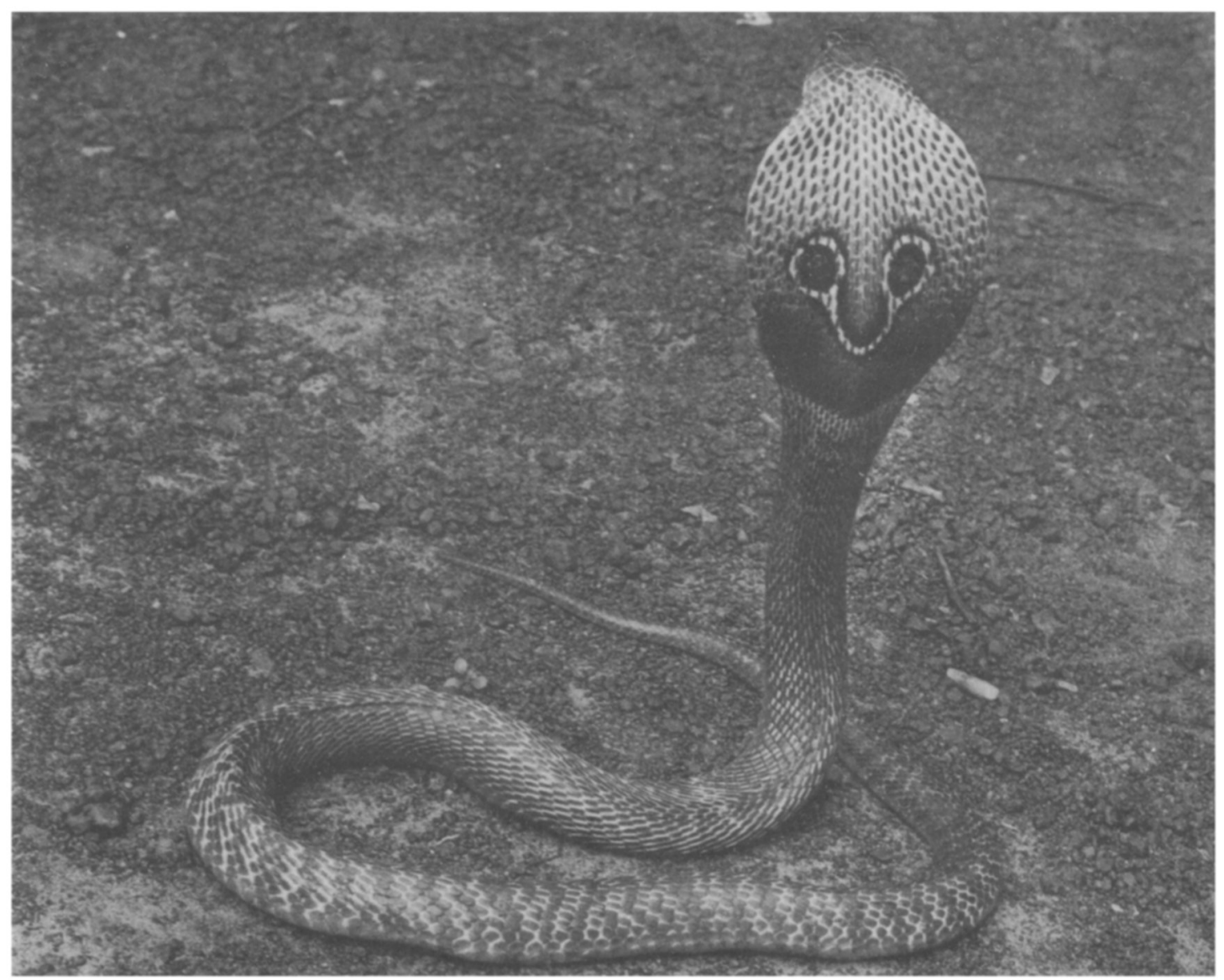


Perhaps in no other country is the snake so closely linked with the mythology of the people as in India. It features importantly in the heroic tales of prehistory, practice of religion, magic and superstition, sculpture and painting, and in many other facets of their lives. Often, it appears in a benevolent role. Snake worship is still practised. Yet, in apparent contradiction, the snake is universally feared and subjected to instant assault wherever it is found. It is one of the aims of the Madras Snake Park to lessen or remove, in time, this unreasoning fear of all snakes in the south. If this end could be achieved, the Trustees believe it could go a long way in stopping the decimation of the snake population as the human intrusion into their habitats increases rapidly.

The Park had its genesis in the small private collection started by Romulus Whitaker in 1969 , in Tambaram, near Madras, supported by a small grant from the World Wildlife Fund. This created enough interest for the collection to evolve into a nucleus for a snake park. The establishment of the Park itself was made possible by the Tamil Nadu Forest Department's grant of an acre $(0.405 \mathrm{ha})$ of land within the Deer Sanctuary in Guindy, on the outskirts of Madras. An 11-person Trust was formed in 1971.

From its inception, the Trust aimed to make the general public aware that snakes had an important ecological role to play; to remove the blind fear of all snakes, frequently derived from tradition and hearsay; to impress on people's minds that only a small number of them were poisonous; to focus the attention of the Government of India on the need to stop the annihilation of snakes everywhere to support a freebooting snakeskin industry which was estimated to have exported ten million skins in 1967-68, a peak year; to persuade the Government to protect the habitats of species like the king cobra and other rain forest snakes as these habitats came under threat; to inform the public that for the bites of the more common venomous snakes anti-snake bite serum was available even if not universally, and bites were not usually fatal unless a large dose of venom had been injected; and, to display, in the Park, as many live specimens of Indian snakes as possible in their natural habitats, and specimens of the entire range of snakes in India in a herpetological museum. Once people are able to tell a 80

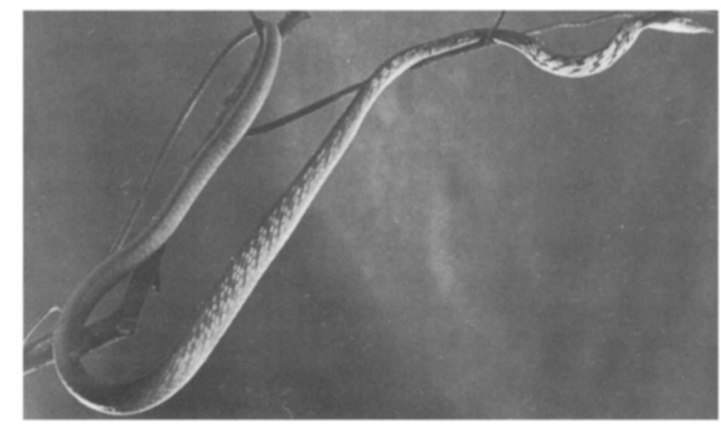

Green vine snake, which displays its chequered pattern under stress (M. Krishnan).

dangerous snake from the large number of harmless ones, they will be freed from the fear of all snakes.

There are 236 species of snakes in India, ranging in size from the 6-m long pythons to the tiny, $100-\mathrm{mm}$ worm snakes. They occur in every known habitat the country affords, in the Himalayas, in the jungles, plains, swamps, farmlands, and deserts, and in the warm coastal seas. Most are found in specific regions only; a small number are widespread. Again, only a few are poisonous: the krait (seven species including the banded krait), the cobra (spectacled, monocled, and black), the king cobra, Russell's, sawscaled, and pit vipers (18 species of the last), the coral snake (five species), and the sea snakes. Most of these are regional, with only the common krait Bungarus caeruleus, the spectacled cobra Naja naja naja, Russell's viper Vipera russellii, and the sawscaled viper Echis carinatus common to all India. The distribution of venomous snakes is of importance in educational programmes: a child in southern India has no need to commit to memory the markings of a banded krait which occurs only

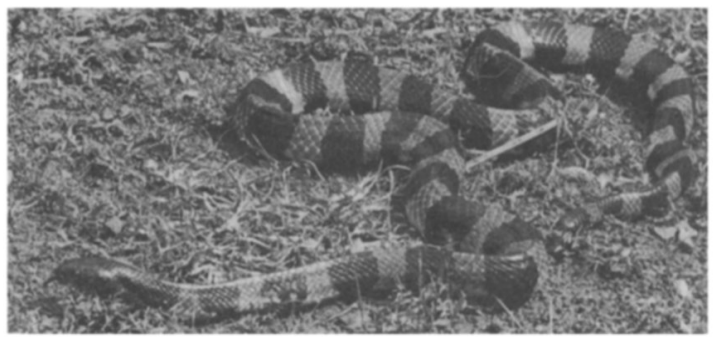

Banded krait, a very poisonous but timid snake from northeast India (M. Krishnan). 
in eastern India. Most of the non-poisonous snakes are harmless and can be safely handled.

But the dread of all snakes is such that any snake, wherever seen, is attacked instantly by any weapon that is at hand and slain brutally. To an extent, the fear is justified: mortality from snakebite is high, estimated as high as 7000-8000 annually, and death from it is horrific. Most of the casualties are from the countryside, in the paddy, wheat and corn fields, vegetable gardens, and scrub jungle where people walk about barefoot. Snakes attack in self-defence when surprised: three-quarters of the bites are at night. Treatment is by ineffectual local remedies or by recourse to magic: there is little knowledge that an antivenom serum exists. Time and lack of transport to remove the patient to the nearest rural hospital further precludes effective aid. Deaths occur, too, from the bites of non-poisonous snakes, from shock, thus adding to the popular belief that all snakes are dangerous.

Anti-snake bite serum is made by the Haffkine Bio-pharmaceutical Corporation of Bombay by hyperimmunising horses against the venoms of the four common poisonous snakes. Lyophilised serum is very stable and can be stored in a cool, dark place without loss of potency for some five years, an ideal quality for keeping in rural dispensaries where there may be no facilities for cold storage. The serum is now stocked in all Government hospitals, and it is more than ever necessary to let the people know.

So, dissemination of information is one of the Park's main aims. The Trustees recognise that adult men and women are already conditioned to an encompassing fear of snakes and will never wholly get over it. Educational programmes are directed to the young: if they begin to appreciate that most snakes are harmless, they might leave them alone to pursue their very useful and economic function of keeping the rodent population in check. Rodents have multiplied so alarmingly that one reputed naturalist has estimated that they destroy as much as a quarter of the country's grain production. Side by side, the ability to identify the poisonous snakes by the young would be invaluable in the case of bites.

Results of the Park's work over the nine years of its existence are striking. A brake has been applied to the export of snakeskins: the Export To save the snake

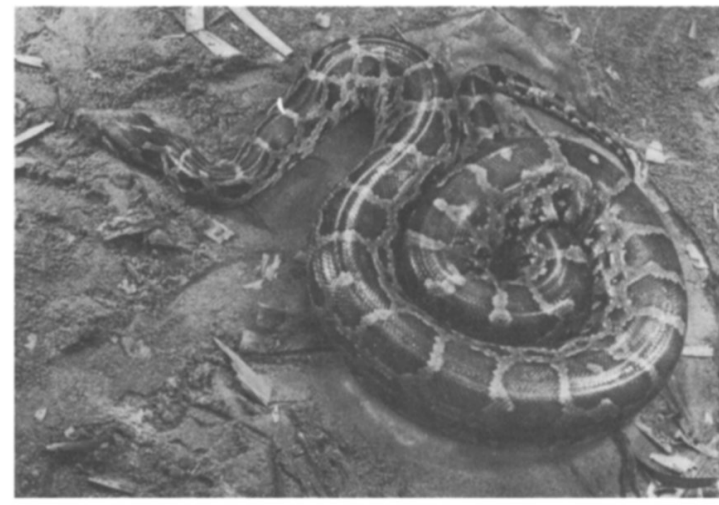

Indian python Python moluris (M. Krishnan).

Policy for Wildlife Products 1975-76 prohibits the export of snakes and snake products without special licence. School educational programmes by visits to the Park, lectures, radio talks and TV films are creating interest in the young. The Park has the nucleus of a research unit and a library, and a considerable collection of specimens for its proposed herpetological museum. It plans to conduct a number of research projects: the interaction between snakes and rodents; sea snakes in the coastal waters; and others. The Trust is also engaged in conservation efforts to save other reptilians - crocodiles, turtles, skinks, and lizards. There is no direct involvement by herpetologists from abroad, although there are occasional shortterm visits by naturalists. The Trustees have the intention to translocate the Park to a larger piece of land where it could display more snakes in their natural habitats and also house its growing collection of specimens. Finance derives from the many thousands of visitors who now visit the Park each year, and grants from Government and donors.

The Director of the Park is Dr M.V. Rajendran, who has written an excellent work on Indian snakes in Tamil. Park affairs are administered by Mr A.N. Jagannatha Rao, a well-known conservationist. The Board of Trustees includes representatives from the Tamil Nadu Forest and Tourist Departments and the Government of India, naturalists, a lawyer, and a chartered accountant: a good balance of expertise to evolve Park policies and plan their fulfilment.

Diana Seshadri, 19 Brookview Road, London SW16 6UA, UK. 